calories in any of the groups surveyed. 'The very satisfactory figures for iron, vitamin $\mathbf{B}_{\mathbf{1}}$, and nicotinic acid are to be attributed to the use of high-extraction $(85-90 \%)$ flour. 'The consumption of vitamin $\mathrm{C}$ was also satisfactory in all groups except the poorer families in the Dublin slums. The principal source in Irish diets is the potato and it is likely that the restriction of cooking facilities in slum rooms is the explanation for the deficiencies noted. Riboflavin intake was also somewhat below the requirement figure in the lower-income groups of towns.

There is evidence of more widespread defects for calcium and vitamin A. As might be expected, the position with calcium was most serious amongst the lower-income groups of towns, particularly Dublin, where the full requirement was not satisfied until the income reached 30 s./head/week. This is related to the low intake of milk and the position would have been even worse were it not for the addition of acid calciumphosphate to baker's flour at the rate of $24 \mathrm{oz}$./sack about half-way through the Dublin survey. This practice is still in operation but at the reduced rate of $14 \mathrm{oz}$./sack, so that the calcium intake in Dublin is probably somewhat higher now than the average figures for the survey suggest but the difference cannot be very great. Neither for this nutrient nor for iron was any allowance made for factors that might affect availability. The unsatisfactory intake of calcium is interesting in view of the high incidence of rickets in Dublin at, and for a few years before, the time of the Dublin survey.

The various instances of deficiency in vitamin $A$ intake were due to the small consumption of green vegetables.

\title{
REFERENCES
}

Department of Health (Republic of Ireland) (1949a). Methods of Dietary Survey and Results from Dublin Investigation. Dublin: 'The Stationery Office.

Department of Health (Republic of Ireland) (1949b). Dietary Survey of the Congested Districts. Dublin: The Stationery Office.

Department of Health (Republic of Ireland) (1950a). Dietary Survey of Large and Small Towns. Dublin: The Stationery Office.

Department of Health (Republic of Ireland) (1950 b). Dietary Survey of Farming Families. Dublin: The Stationery Office.

Magee, H. E. (1945). J. med. Ass., Eire, 17, 98.

\section{Agricultural Implications of the Results of the Irish National Nutrition Survey}

\section{By E. J. Shreny, University College, Dublin}

This country, in portions of which the dietary survey under review was conducted, is predominantly agricultural. Mixed agriculture, that is to say tillage cropping and animal production, is practised, and the excess of total food produced over the human food requirements of the country is reflected in the fact that some $70 \%$ of the annual exports take the form of human food, mainly livestock and livestock products. Normally we import a considerable proportion of our bread grain though, during the war and subsequently, home production was made to meet the greater part of our requirements. To supplement the coarser grains produced at home we import animal foods, including maize; since the resulting animal products are exported to feed people elsewhere, this is considered good economy, and an appropriate flow of trade in human and animal foods. 
Though such conditions provide for an adequate supply of food for the human population of the country, they do not necessarily make available to the people of every district a sufficiency of each of the nutritive ingredients essential for optimum conditions of health. The purchasing power of individual families, the level of knowledge of nutritional requirements, the food items available locally, and local dietary customs make for considerable variation in the relative amounts of the different foodstuffs consumed, as well as in the calorific value of the daily consumption.

The report (Department of Health (Republic of Ireland), 1949a, $b, 1950 a, b$ ) shows up certain deficiencies in the diet of the people of Dublin (see also Jessop, 1950). There is a slight shortage in the intake of vitamin $\mathrm{A}$, riboflavin, and vitamin $\mathrm{C}$ among the low-income groups, and there is a serious shortage of calcium intake by the greater part of the population of the city. The deficiency of calcium, and indeed of vitamin A and riboflavin also, is associated with the comparatively low consumption of milk, namely $4.8 \mathrm{pt}$./diet-head/week. The seasonal shortage of milk in Dublin during the winter months has been referred to in the report (Department of Health (Republic of Ireland), I $949 a$ ). That seasonal shortage was associated with the wartime emergency conditions of shortage of protein food for cattle and it disappeared at the end of the war. For the past two winters there was more milk produced in the Dublin supplyarea than the city was able to absorb. Actually there was no shortage of supply during the period of the Dublin survey which began in April 1946. In April 1946 some $8, \infty 00,000$ gal. milk were converted into butter in this country, and the production of butter increased three times in the subsequent months. At that time dairymen got Is. 9d./gal. for milk for liquid consumption, while the price of milk for butter-making

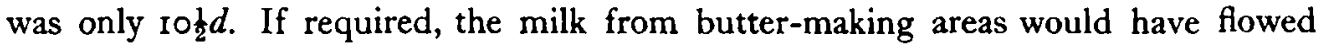
to Dublin because arrangements existed whereby such a flow could have taken place. The consumption of milk in Dublin during the period of the survey was certainly not limited by the unavailability of the milk.

The greater consumption of milk on the farms, namely $9 \cdot 2 \mathrm{pt}$./diet-head/week, as against $4.8 \mathrm{pt}$. in Dublin is explained by dietary custom and by the difference in price. On the farm, milk was available at $10 \frac{1}{2} d$./gal. or $\mathrm{s} \cdot 3 d . / \mathrm{pt}$. In Dublin the retail prices were: during the first half of the survey period, $3 \frac{3}{4} d . / p t$. delivered in bottle at the door and $2 \frac{3}{4} d$. loose in the shop; during the second half of the survey period, $4 \frac{1}{d} d . / p t$. in bottle delivered and $3 \frac{1}{4} d$. loose in the shop.

The supply of milk to Dublin since the war has increased from 40,000 to $56,000 \mathrm{gal}$./ day. In the meantime there has, however, been a considerable migration of people to the city. The desirable further increase in the daily milk consumption to about 90,000 gal. would, from the agricultural point of view, provide an extended market for dairymen and would be a means of raising the efficiency of the cow. Where butter is made and the separated milk fed to pigs, the cow's efficiency, i.e. the calorific value of the butter and pig meat produced is only about $15 \%$ of the calorific value of the food consumed by the cow. When the milk is directly consumed by man the cow's efficiency is approximately $25 \%$.

The deficiency of vitamin $\mathrm{C}$ in the Dublin diet as compared with that on the farms is associated with the smaller consumption of potatoes and other vegetables. The 
weekly consumption figures per diet-head were as follows: potatoes, in Dublin 82.7 oz., on farms I62.7 oz.; vegetables, in Dublin 27.4 oz., on farms $37^{\circ} 1 \mathrm{oz}$. At the time of the survey surplus potatoes were being fed to livestock so that the comparatively low intake in Dublin, where the market price was considerably higher than the price obtainable for the potatoes fed to livestock, was not explainable by unavailability. With vegetables the comparatively low intake would be explainable in the early part of the survey period, April and May, by shortage of supply and high price: these reasons would not apply, however, in the subsequent months.

'The comparatively very low consumption of cheese in Dublin, on farms, in the towns and in the congested districts, has been referred to (Department of Health (Republic of Ireland), I949 $a, b, 1950 a, b$; Jessop, 1950). In each of the years 1945 and 1946 some $59,000 \mathrm{cwt}$. of cheese were made in the country. A rough calculation, applying the consumption figures as given in the survey to the whole country, puts the total consumption as approximately equal to the annual production at that time. It is difficult to say in how far the consumption of cheese was limited by available supplies. I should say the shortage and absence of variety was an operating factor, though, on the whole, the people of this country are not at any time large consumers of cheese.

In the congested districts of the western seaboard the proportion of arable land is low, the soil is naturally poor, and the holdings very small. Congestion has existed there since the ancestors of the present population were driven from the east and midland counties by war and conquest. 'The small income from the farm is supplemented by income from labour performed elsewhere and, for coastal dwellers, from fishing. 'The livestock population is low, though on most holdings, with the exception of the smaller ones, there is a cow or two, sometimes a few pigs and on all holdings there is poultry. On the very limited tillage area potatoes and a little cereals are produced; the amount of other vegetables grown is small. In these parts the people live largely on the foods available locally and, mostly, on the supplies available from their own little holdings. Supplies are flush in the autumn: with the exception of potatoes they have dwindled by spring and, in my opinion, this almost entirely explains the reduced consumption of food in the congested districts in spring as compared with autumn. The reduction in the consumption of milk, fats, fish, vegetables, and preserves bears out this contention.

Appreciably fewer vegetables were consumed in the congested districts, even in the autumn, than in Dublin. 'The explanation is that only a small quantity of vegetables is grown locally. Even in the large and small towns less vegetables are consumed than in Dublin. At least part of the explanation there too is local unavailability. 'To the Dublin vegetable market, there is a regular supply from local markets. In Dublin there is a high retail price, whereas on the farm, where consumption is appreciably higher, vegetables are available at cost of production.

\section{REFERENCFS}

Department of Health (Republic of Ireland) (I949a). Methods of Dietary Survey and Results from Dublin Investigation. Dublin: The Stationery Office.

Department of Health (Republic of Ireland) ( $1949 b$ ). Dietary Survey of the Congested Districts. Dublin: The Stationery Office. 
Department of Health (Republic of Ireland) (1950a). Dietary Survey of Large and Small Towns. Dublin: The Stationery Office.

Department of Health (Republic of Ireland) (1950b). Dietary Survey of Farming Families. Dublin: The Stationery Office.

Jessop, W. J. E. (1950). Brit. J. Nutrit. 4, 28 I.

\section{Haemoglobin and Plasma-Protein Values in 2500 Adults and 600 Pregnant Women in the Republic of Ireland}

\section{By T. E. Bradshaw, Royal College of Surgeons in Ireland, St Stephen's Green, Dublin}

Investigations were carried out on two groups of individuals. The first group consisted of adult men and women mostly from provincial districts of Ireland, who were anxious to migrate to Great Britain for the purpose of obtaining employment. The Irish Government considered it advisable for them to submit to a physical examination before leaving the country and insisted that this examination be carried out before a travel permit would be granted. The applicants for permits were examined in the evenings at two centres, one for men and another for the women. At the time of examination certain details were recorded which might be of interest in the Irish National Nutrition Survey (Department of Health (Republic of Ireland), I949a, $b$, I950a, $b$ ), and samples of $3 \mathrm{ml}$. venous blood were taken, transferred to an oxalated tube and sent by messenger to the Rotunda Hospital laboratory where haemoglobin estimations were carried out the same evening. In this group a total of 1107 males and 1432 females was investigated.

The second group consisted of women in various stages of pregnancy who were attending the Out-Patient Department of the Rotunda Hospital. As part of the hospital routine samples of venous blood are taken from all such patients, and in each of these cases a $3 \mathrm{ml}$. portion was transferred to an oxalated tube. Haemoglobin estimations were carried out the same evening. A total of approximately 600 samples was investigated.

In both these groups, plasma proteins were also determined on about half the total number of subjects.

\section{Methods}

In all cases haemoglobin estimations were done by the alkaline-haematin method. The colour intensities were determined in a Spekker absorptiometer against the Gibson-Harrison standard, kindly supplied by Prof. D. C. Harrison, Queen's University, Belfast. In a number of cases the haemoglobin was also determined by the acid-haematin method and good correlation was obtained.

In about half the number of each group, haemoglobin values and also plasma-protein values were obtained from the densities of the whole blood and plasma by the coppersulphate method of Phillips, Van Slyke, Dole, Emerson, Hamilton \& Archibald (1945).

\section{Results}

In Table $\mathrm{r}$ the results of the haemoglobin survey are given in such a way as to show the distribution of the values over the whole sample. The figures for adult men and women will be considered first. Though it is clear that the great majority of the subjects 